\title{
Unemployment Insurance in Unionized Labor Markets: Neither Ghent nor Centralized
}

\author{
David Saha \\ Ronnie Schöb
}

CESIFO WORKING PAPER NO. 5430

CATEGORY 4: LABOUR MARKETS

JULY 2015

An electronic version of the paper may be downloaded

- from the SSRN website:

- from the RePEc website:

- from the CESifo website:

wWw.SSRN.com

Www.RePEc.org

www.CESifo-group.org/wp 


\title{
Unemployment Insurance in Unionized Labor Markets: Neither Ghent nor Centralized
}

\begin{abstract}
This paper analyzes unemployment insurance (UI) schemes in the presence of mobile workers and trade unions at industry or regional level that are capable of internalizing the effect of wage demands on UI contribution rates. We compare two types of existing UI systems. When UI is organized at trade union level (decentralized Ghent UI), trade unions strategically lower the benefit levels of their UI schemes to deter welfare recipients from other unions from entering their UI scheme, leading to a race to the bottom in UI provision. With centralized provision of UI, by contrast, trade unions do not fully account for the cost of higher wages as mobility allows them to partially shift the burden of unemployment to other UIs. A system of coordinated UI, combining a centrally set benefit level with decentralized funding as in Ghent UI systems, can circumvent both the strategic benefit setting and the fiscal externality problems, thus reconciling the equity and efficiency aims in the design of unemployment insurance.
\end{abstract}

JEL-Code: J510, J610, J650, H700.

Keywords: unemployment insurance, Ghent system, trade unions.

David Saha

School of Business \& Economics

Free University Berlin

Boltzmannstr. 20

Germany-14195 Berlin

david.c.saha@gmail.com
Ronnie Schöb*

School of Business \& Economics

Free University Berlin

Boltzmannstr. 20

Germany - 14195 Berlin

ronnie.schoeb@fu-berlin.de

*corresponding author

July 2015

We would like to thank Thomas Aronsson, Friedrich Heinemann and Marcel Thum for valuable comments and suggestions. The usual disclaimer applies. 


\section{Introduction}

Should redistributive schemes be centralized if factors are mobile between different jurisdictions? There are strong arguments that, as factor mobility increases, decentralized systems of income redistribution may come under pressure as net recipients might move into more generous redistribution schemes while net contributors might leave them (see e.g. Sinn 2000). Decentralized social protection then faces a "race to the bottom" that would threaten its existence . A centralized redistributive system such as public unemployment insurance would eliminate this pressure. However, the centralization of public unemployment insurance may also reduce incentives for decentralized wage setting actors to actively combat unemployment (see Dolls et a. 2014 and Vetter 2014).

In the European Union, social security systems and hence the provision of unemployment insurance in the EU are presently the sole responsibility of individual members states. There is an ongoing debate to what extent unemployment insurance as well as other redistribution schemes should be reorganized on a centralized European level, thus complementing European economic integration by a European social contract. A European unemployment insurance system is advocated not only to counteract downward pressures on decentralized insurances, but also as an insurance against idiosyncratic shocks as it works like an automatic stabilizer that automatically generates transfers from booming to languishing countries (see Dullien 2007 and van Rompuy et al. 2012).

In this paper, we analyze the question of centralization or decentralization of unemployment insurance in unionized labor markets with mobile workers and later interpret our findings with regard to the question of centralization of unemployment insurance in the EU. In unionized labor markets, a centralized unemployment insurance allows multiple trade unions that negotiate wages at regional or industry level to partially externalize the cost of higher wages. This in turn leads to higher aggregate unemployment (see e.g. Holmlund and Lundborg 1999) than would result from decentralized unemployment insurance schemes. Using a right-to-manage model in which trade unions set wages and firms then decide on employment, we analyze how the centralization of unemployment insurance systems (UI) affects labor market outcomes and welfare, depending on the degree of labor mobility. The contribution of this paper is threefold. We first show that a decentralized unemployment insurance system organized on the level of individual trade unions (a so-called Ghent UI system) is not sustainable at the same degree of insurance if labor is mobile and welfare 
migration motivated by the generosity of unemployment benefits exists. It is a wellestablished result in the literature that, without labor mobility, such a UI system induces wage moderation and thus relatively low unemployment. With labor mobility and welfare migration, however, such a decentralized system of UI will face a "race to the bottom". When the own UI becomes a welfare magnet, setting lower benefit levels can deter immigration of unemployed people into the UI system. Secondly, we show that a centralized system of UI covering the members of all trade unions inhibits detrimental welfare migration but leads to excess unemployment. In such a system, small, regional or sector-specific trade unions can externalize part of the unemployment costs that would result from higher wages through the common contribution rate levied to finance unemployment benefits. These two results reveal an apparent dilemma of UI centralization - the choice between negative labor market effects of centralized UI and a race to the bottom in the provision of decentralized Ghent UI. The third contribution of this paper is to show that this dilemma can be dissolved by a system of coordinated UI, in which benefit levels are coordinated while the funds and contribution rates remain decentralized: coordinating the benefit levels removes the incentives for welfare migration, while decentralizing the contribution rates leads to wage moderation, as small unions not only receive the full benefits of any wage increase but also have to bear the respective cost in full.

The paper is organized as follows: Section 2 reviews the relevant literature on which this paper builds. Section 3 presents the basic model. Section 4 analyzes the merits of Ghent UI with regard to its effects on wages and employment and its breakdown under welfare migration. Section 5 shows that the fiscal externality inherent in a centralized UI system leads to higher gross wages and higher unemployment. In section 6, we then consider a coordinated system of UI that is capable of combining the positive employment effects of Ghent UI with sustainability under factor mobility. The results are summarized and their application to the EU real-world context is discussed in section 7.

\section{Literature review}

This paper builds on two different strands of literature, one regarding the effect of union centralization on gross wages and unemployment, and the other concerning decentralized redistribution in the presence of factor mobility. 
The literature on union centralization argues that the higher the degree of union centralization in an economy, the larger the effect of one union's wage is on tax or UI contribution rates through the budget constraint of the government or UI system. As unions should consider this effect in their decisions on their preferred wages, it should, ceteris paribus, lead centralized unions to set lower wages than decentralized unions (Calmfors and Driffil 1988, who first suggested this effect non-formally, Alesina and Perotti 1997, Gibbons and Freeman 1995 and Groot 2001). “Tax internalization” (Groot 2001) of more centralized unions thus drives down union wage demands. Empirical evidence generally supports a negative relationship between union centralization and unemployment. While earlier papers found a hump-shaped relationship between wages and the degree of centralization due to a countervailing “market power” effect (Calmfors and Driffil 1988, Alesina and Perotti 1997), the later literature finds that gross wages are monotonously decreasing in the degree of union centralization (Nickell and Layard 1999). Our approach builds on the idea of tax internalization, but takes the degree of union centralization as given. ${ }^{1}$ Instead of considering different degrees of union centralization, however, we consider different degrees of UI centralization.

In order to enforce tax internalization by unions, an alternative to centralizing collective bargaining is decentralizing the UI system. This is suggested by the literature on the Ghent UI system (named after the Belgian town in which it was first implemented), in which UI is provided by trade unions to its members. Ghent UI, which exists in Denmark, Finland, Sweden and Belgium², typically “denotes a system of voluntary unemployment insurance that is subsidized by public authorities and in which trade unions (or linked funds) provide benefits to the unemployed" (van Rie et al. 2011, p.127). Theoretical analyses show that this system of UI leads to internalization of the fiscal costs of unemployment by unions and thus to lower wages and higher employment levels (Holmlund and Lundborg 1999 and Dimick 2012). The favorable employment effects in this system become larger as government

\footnotetext{
${ }^{1}$ Note that the institutional structure of collective bargaining is in general very difficult to change and only very few systems of collective bargaining centralized at national level exist. In 2000, out of 20 OECD countries, only in Ireland and the Netherlands centralized or nationally coordinated collective bargaining was practiced (Nickell 2006). Centralized bargaining, although recommended by the aforementioned theoretical literature, is difficult in practice, as such systems suffer from inflexibility and enforcement problems (Katz 1993, Gibbons and Freeman 1995).

${ }^{2}$ In Belgium, trade unions administer the funds of the unemployment insurance, but eligibility to benefits does not depend on union membership (Böckerman and Uusitalo 2006). With regard to the arguments in this paper, the Belgian UI functions exactly as any other Ghent system.
} 
subsidies to the system, contingent on unemployment levels, are reduced (Holmlund and Lundborg 1999).

Another strand of literature casts doubt on the sustainability of decentralized redistribution schemes. According to Sinn (2000), increasing mobility of persons allows those individuals making a net contribution to a redistributive system to move to less redistributive systems, where they will face lower contribution rates, while the reverse holds for net beneficiaries from redistributive systems, who move to more generous systems. The strain this imposes on the budgets of more generous welfare states may result in a downward adjustment of welfare standards. Theoretical work largely focuses on the impact of labor mobility on redistribution through income taxation, mostly concluding that labor mobility will lead to a dismantlement of, or downward pressure on decentralized redistribution (Sinn 2000 or Cremer and Pestieau 2003 for a review of the literature and a benchmark model). Concerning factor mobility and redistribution through UI, Lejour and Verbon (1996) show in a two-country model of UI and capital mobility that capital mobility leads to lower UI coverage than is chosen by a rentmaximizing government under autarky. The upshot of the theoretical literature on factor mobility and redistribution is that, unless factor mobility is restricted ${ }^{3}$, redistribution needs to be centralized in order to be sustained.

The available empirical evidence is not entirely conclusive. Several papers indicate that welfare migration may be of relatively small magnitude. Nevertheless "welfare magnets" attract migrants, particularly those with lower skills and higher welfare participation rates (Borjas 1998, Brücker et al., 2002, de Giorgio and Pellizzari 2006, Razin and Wahba, 2011). More recent research, however, does not find a significant effect of welfare state variables on migration decisions (Skupnik, 2014, Beine et al., 2011). The hypothesis of the "race to the bottom” itself, be it because of real or perceived welfare migration, is supported by the empirical literature, with most studies inferring that at sub-national level, strategic benefit level setting does occur (e.g. Brueckner 2000, Dahlberg and Edmark 2008). At national level, there is some evidence that in anticipation of higher labor mobility due to EU enlargement, EU-15 countries tightened entitlement rules for social assistance (Kvist 2004, Skupnik, 2014).

In what follows, we provide a framework that allows us to combine the driving forces described by the two strands of literature - strategic unemployment benefit setting in the

\footnotetext{
${ }^{3}$ Sinn (2000) suggests that, whilst retaining mobility of individuals among states, a "home country principle" of taxation where an individual will always pay taxes in and receive benefits from his/her home country, which effectively curtails mobility between redistributive systems.
} 
presence of welfare migration and wage setting in a potentially shared UI system - in a consistent model, enabling us to propose a UI system that avoids the pitfalls described by either strand of literature.

\section{The model}

We consider a model to analyze either mobility between industries or regions. In the first case, the model refers to industry-wide unions, in the second case to a region-wide unions, with each single union negotiating wages for all sectors within its region. In line with the literature on Ghent trade unions (e.g. Holmlund and Lundborg, 1998), on which we build, we will refer to trade unions at industry level while keeping the second interpretation in mind. We consider an economy with multiple, symmetric industries $i=1,2, \ldots, N$ in each of which $\bar{L}_{i}$ risk-averse workers are organized in a monopoly trade union that unilaterally sets the wage. Firms then determine employment. ${ }^{4}$

Workers' preferences are described by a utility function $u$ with $u^{\prime}>0, u^{\prime \prime}<0$, where utility is derived from net labor income that equals the gross wage $w_{i}$ minus the contribution paid to the UI system $t_{i} w_{i}$ when employed and from unemployment benefits $b_{i}$ plus the money equivalent of leisure $\tilde{b}$ when unemployed. Labor demand in sector $i$ is given by the function $L_{i}(w)$ for which we assume a constant labor demand elasticity $\eta .^{5}$ The trade union maximizes the sum of the utility of employed and unemployed members: ${ }^{6}$

$$
\Omega_{i}\left(w_{i}\right)=L_{i}\left(w_{i}\right) u\left(\left(1-t_{i}\right) w_{i}\right)+\left(\bar{L}-L_{i}\left(w_{i}\right)\right) u\left(b_{i}+\tilde{b}\right) .
$$

Workers will only accept a job when the utility from working is not less than the utility derived from being unemployed. The incentive compatibility of working is thus given by

$$
u\left(\left(1-t_{i}\right) w\right) \geq u\left(b_{i}+\tilde{b}\right)
$$

\footnotetext{
${ }^{4}$ Since we exclusively focus on effects that do not affect firms' profits, the monopoly trade union model in which trade unions unilaterally set wages leads to the same qualitative results as models applying Nashbargaining between trade unions and firms (see Holmlund, Löfgren and Engström 1989).

${ }^{5}$ We assume throughout our analysis that labor demand in each industry is independent of the wages set in all other industries. This simplification is justified since we concentrate on the effects of different UI systems on labor market outcomes, for which possible cross-wage effects are not relevant. Such effects are of importance when the issue of union centralization or coordination is under investigation (see e.g. Calmfors and Driffill (1988).

${ }^{6}$ We use the model of a "utilitarian" trade union (cf. Oswald, 1985), as it combines intuitive clarity of the objective function (maximization of the sum of members' utility) with analytical tractability and is the most widespread model of trade union behavior in the literature.
} 
Throughout the paper, we assume that $\bar{L}_{i}$ is large enough for all $i$ such that unemployment exists in all industries given the wage setting by unions, that all systems of UI have a binding budget constraint and that the unemployment insurance contribution rate $t_{i}$ is set endogenously to finance a given benefit level $b_{i} \cdot{ }^{7}$ The budget constraint on the industry level is then given by

$$
t_{i} w_{i} L_{i}\left(w_{i}\right)=b_{i}\left(\bar{L}-L_{i}\left(w_{i}\right)\right) \text {, }
$$

whereby the functional form of the contribution rate $t_{i}$ depends on the particular design of the unemployment insurance system both at sectoral and aggregate level.

Welfare may be affected in two ways. First, total rents from production are maximized when marginal labor productivity equals the marginal utility of leisure. Since firms adjust employment such that the wage equals marginal productivity, the efficient employment level is reached when $w=\tilde{b}$. If $L(w)<\bar{L}$ and the wage exceeds the social opportunity cost of working, $w>\tilde{b}$, involuntary unemployment occurs and total rents from production become smaller. Second, welfare is also affected by income differences between employed and unemployed individuals. Welfare maximization requires that the risk-adverse workers' income is the same, irrespective of their employment status, i.e. $\left(1-t_{i}\right) w_{i}=b_{i}+\tilde{b}$. This can be achieved by introducing full unemployment insurance.

\section{The Ghent unemployment insurance scheme and the race to the bottom}

\subsection{Ghent UI without labor mobility}

Ghent UI is an unemployment insurance scheme that is managed by the trade union. Without inter-union mobility of workers, each union $i$ can freely choose both the gross wage $w_{i}$ and the unemployment benefit $b_{i}$ that maximizes its objective function and then has to set the contribution rate to balance the budget constraint of the UI. Thus, the trade union maximizes its objective function with respect to both $w_{i}$ and $b_{i}$ so that we have

$$
\max _{w_{i}, b_{i}} \Omega_{i}\left(w_{i}\right)=L_{i}\left(w_{i}\right) u\left(\left(1-t_{i}\left(w_{i}, b_{i}\right)\right) w_{i}\right)+\left(\bar{L}-L_{i}\left(w_{i}\right)\right) u\left(\left(b_{i}+\tilde{b}\right)\right),
$$

s.t.

$$
t_{i}\left(w_{i}, b_{i}\right) w_{i} L_{i}\left(w_{i}\right)=b_{i}\left(\bar{L}-L_{i}\left(w_{i}\right)\right)
$$

\footnotetext{
7 Note that all results would hold if the tax rate was kept constant and the benefit levels were adjusted accordingly.
} 
The first order condition with respect to $b_{i}, u^{\prime}\left(\left(1-t_{i}\left(w_{i}, b_{i}\right)\right) w_{i}\right)=u^{\prime}\left(b_{i}+\tilde{b}\right)$ only holds if the trade union chooses full insurance for its workers, i.e.

$$
\left(1-t\left(w_{i}, b_{i}\right)\right) w_{i}=b_{i}+\tilde{b}
$$

The wage level set by the union is determined by the first order condition

$$
\begin{gathered}
\Omega_{i w_{i}}=\eta\left[u\left(\left(1-t_{i}\left(w_{i}, b_{i}\right)\right) w_{i}\right)-u\left(b_{i}+\tilde{b}\right)\right] \\
+w_{i} u^{\prime}\left(\left(1-t_{i}\left(w_{i}, b_{i}\right)\right) w_{i}\right)\left[1-t_{i}\left(w_{i}, b_{i}\right)-w_{i} \frac{\delta t_{i}\left(w_{i}, b_{i}\right)}{\delta w_{i}}\right]=0 .
\end{gathered}
$$

Substituting the partial derivative $\partial t_{i}\left(w_{i}, b_{i}\right) / \partial w_{i}$ from (3a) and applying the full insurance result, for any trade union $i$, (6) simplifies to (whereby superscript ga indicates the results for Ghent UI under autarky, i.e. without labor mobility)

$$
w_{i}^{g a}=\frac{\eta}{1+\eta} \tilde{b}
$$

In the Ghent UI, the monopoly trade union maximizes the labor rent for the trade union by setting a monopoly wage that exceeds the marginal utility of leisure: $w^{g a}>\tilde{b}$. The union then equally distributes the acquired labor rent among employed and unemployed members. Each Ghent UI will thus provide full insurance at the labor rent-maximizing wage. The resulting benefit level for its workers is then given by

$$
b^{g a}=\frac{\eta^{\eta}}{(1+\eta)^{1+\eta}} \frac{\tilde{b}^{1+\eta}}{\bar{L}}
$$

This result is summarized in Proposition 1.

Proposition 1 (Ghent UI): Without labor mobility, a monopoly trade union that runs its own unemployment insurance scheme sets a labor-rent maximizing gross wage rate and provides full unemployment insurance.

Since all unemployment benefits are paid from its own members' contributions, it is optimal for the trade union to set the wage such that it maximizes the labor rent by setting the wage as a constant mark-up over the foregone utility derived from leisure. This leads to lower wages than in the case where unemployment benefits are (partially) paid by some third party. In this latter case, the individuals' opportunity costs of labor equal the foregone utility derived from 
leisure plus the transfers received from the third party. UI schemes thus lead to lower unemployment (cf. Holmlund and Lundborg 1999 and Dimick 2012). However, this result crucially depends on the assumption of no inter-union mobility of workers.

\subsection{Ghent UI, labor mobility and the "race to the bottom"}

Labor mobility refers to mobility across the domains of different trade unions, so that changing industry implies changing the unemployment insurance. This possibility of selfselection by voting with one's feet (Tiebout 1956) leads individuals with low risks to leave comprehensive insurance systems, whilst high-risk individuals are attracted into those systems, leading to a welfare-deteriorating "race to the bottom” of competing insurance systems. Hence, generous UI schemes might induce welfare migration, motivated by the level of high unemployment benefit payments.

We consider 'pure' welfare migration by assuming that welfare recipients are mobile across industries, while the migration of workers is restricted by closed-shop industries. This simplification allows us to focus on the effect of migration induced by the generosity of UI systems on trade unions' wage setting and design of the UI, without having to consider different types of workers with different unemployment risks. The analytical driving force thus remains the same as described by Tiebout: trade unions aim to provide high incomes to their working and unemployed members, whilst trying to discourage migration of welfare recipients into their UI systems.

All individuals face the mobility cost $c$, where $c$ is distributed uniformly between zero and some maximum migration cost $C$. The migration decision of any benefit recipient is thus governed by the benefit level in her native industry, $b_{l}$, the highest available benefit level in industry $k, b_{k}$ and her individual migration cost $c$. She will therefore migrate from $l$ to $k$ if

$$
b_{k}-b_{l} \geq c
$$

Consequently, the stock of migrants in any industry $j$ is thus given by

$$
M_{j}\left(b_{j}, b_{-j}, w_{j}\right)=\left\{\begin{array}{cc}
\frac{\sum_{i-j} \frac{\left(b_{j}-b_{i}\right)}{C}\left(\bar{L}-L_{i}\left(w_{i}\right)\right)}{K} & \text { if } b_{j}=b_{\max } \\
=-E_{j}\left(b_{j}, b_{-j}\right)=\frac{-\left(b_{\max }-b_{j}\right)}{C}\left(\bar{L}-L_{j}\left(w_{j}\right)\right) & \text { if } b_{j}<b_{\max }
\end{array} .\right.
$$


In the first case of $b_{j}=b_{\max }$, the migrants from all industries except $j$ are spread equally over the $K$ industries in which the highest available unemployment benefit level $b_{\max }$ prevails. Note that the formulation implies that no migration occurs between the industries that have set $b_{k}=b_{\max }$. In the second line, $E_{j}\left(b_{j}, b_{-j}\right)=-M_{j}\left(b_{j}, b_{-j}\right)$ is a shorthand for the number of emigrants from industry $j$ if the benefit level is set below $b_{\max }$. The budget constraint of the unemployment insurance fund of industry $i$ now includes the migrant stock in industry $i$ as unemployment benefit recipients.

$$
t_{i}\left(w_{i}, b_{i}, b_{-i}\right) w_{i} L_{i}\left(w_{i}\right)=b_{i}\left(\bar{L}-L_{i}\left(w_{i}\right)+M_{i}\left(b_{i}, b_{-i}\right)\right) .
$$

Note that, due to equation (10), the derivative of the contribution rate with respect to the benefit level depends on the relative size of $b_{i}$, compared to the benefit levels in the other industries. If $b_{i}=b_{\max }$ (for $K=1$ ), we have, for a marginal increase in $b_{i}$,

$$
\frac{\delta t_{i}\left(w_{i}, b_{i}, b_{-i}\right)}{\delta b_{i}}=\frac{\bar{L}-L_{i}\left(w_{i}\right)+M_{i}\left(b_{i}, b_{-i}\right)}{w_{i} L_{i}\left(w_{i}\right)}+b_{i} \frac{\sum_{j-i}\left(\bar{L}-L_{j}\left(w_{j}\right)\right)}{C w_{i} L_{i}\left(w_{i}\right)}
$$

For $b_{i}<b_{\max }$, the derivative is

$$
\frac{\delta t_{i}\left(w_{i}, b_{i}, b_{-i}\right)}{\delta b_{i}}=\frac{\bar{L}-L_{i}\left(w_{i}\right)+M_{i}\left(b_{i}, b_{-i}\right)}{w_{i} L_{i}\left(w_{i}\right)}+b_{i} \frac{\bar{L}-L_{i}\left(w_{i}\right)}{C w_{i} L_{i}\left(w_{i}\right)}
$$

If a subgroup of industries $K, \quad N>K>1$, have set the same, highest available unemployment benefit level at $b_{i}=b_{\max }, t_{i}\left(w_{i}, b_{i}, b_{-i}\right)$ behaves discontinuously. A change of unemployment benefit level by union $i$ will lead to the total positive stock of migrants either suddenly concentrating in the unemployment insurance system $i$ (or leaving $i$ 's insurance system).

Trade unions act in the interest of their present members and will set wages and unemployment benefit levels to maximize the expected utility of current workers in their industry, i.e. the utility of incoming migrants does not enter the unions' objective function. Unions take the unemployment benefit levels set by the other unions as given, but take into account that its members may emigrate into the UI systems of other industries or members of other unions may immigrate into their UI system. In the presence of migration, the maximization problem of a trade union $i$ becomes 


$$
\begin{aligned}
& \max _{w_{i}, b_{i}} \Omega_{i}\left(w_{i}\right)=L_{i}\left(w_{i}\right) u\left(\left(1-t_{i}\left(w_{i}, b_{i}, b_{-i}\right)\right) w_{i}\right) \\
& +\left(\bar{L}-L_{i}\left(w_{i}\right)-E_{i}\left(b_{i}, b_{-i}\right)\right) u\left(b_{i}+\tilde{b}\right)+\int_{0}^{b^{\max }-b_{i}} \frac{\left(\bar{L}-L_{i}\left(w_{i}\right)\right)}{C} u\left(b_{\max }+\tilde{b}-v\right) d v .
\end{aligned}
$$

subject to (3b) and (10), where the last term is the utility of all unemployed workers who emigrate because their individual migration costs are less or equal to the difference between the benefit level set by their original trade union and the highest available benefit level, i.e. $c \leq b_{\max }-b_{i}$.

\subsubsection{Equilibria in benefit levels under Ghent UI with labor mobility}

To find out whether the existence of welfare migration leads to a "race to the bottom" in UI provision, in what follows, we will derive the conditions for possible equilibria in the level of unemployment benefits. The unemployment benefit level of union $i$ follows from the first order condition with respect to $b_{i}$,

$$
\begin{gathered}
\Omega_{i b_{i}}=-w_{i} L_{i}\left(w_{i}\right) u^{\prime}\left(\left(1-t\left(w_{i}, b_{i}, b_{-i}\right)\right) w_{i}\right) \frac{\delta t_{i}\left(w_{i}, b_{i}, b_{-i}\right)}{\delta b_{i}} \\
+\left(\bar{L}-L_{i}\left(w_{i}\right)-E_{i}\left(b_{i}, b_{-i}\right)\right) u^{\prime}\left(b_{i}+\tilde{b}\right) \\
-\frac{\partial E_{i}\left(b_{i}, b_{-i}\right)}{\partial b_{i}} u\left(b_{i}+\tilde{b}\right)-\frac{\bar{L}-L_{i}\left(w_{i}\right)}{C} u\left(\tilde{b}+b_{i}\right) .
\end{gathered}
$$

The last two terms cancel out since we have $\partial E_{i}\left(b_{i}, b_{-i}\right) / \partial b_{i}=-C^{-1}\left(\bar{L}-L_{i}\left(w_{i}\right)\right)$.

Although we cannot rule out asymmetric equilibria, in what follows, we only consider symmetric equilibria. In a symmetric equilibrium, unemployment benefit levels are the same in all industries, $b_{i}=b_{\max } \forall i$, so that the stock of migrants in each industry is zero. Consequently, wage and employment levels are also identical across industries. There exists a range of symmetric equilibria, differentiated by the level of UI provision.

\section{The maximum level of UI sustainable in symmetric equilibrium}

The symmetric equilibrium with the highest possible unemployment insurance level follows from (13) by applying symmetry and using (11b). The trade union has no incentive to lower unemployment benefits when the additional benefits for incumbent workers from higher net wages - due to lower unemployment benefits and induced emigration of some unemployment benefit recipients - fall short of the negative impact on unemployed workers' utility due to 
lower social insurance. As $\delta M_{j} / \delta b_{j}$ is constant for any given level of $b_{j}$ and utility is concave in income, the lower $b_{j}$, the stronger the negative impact of lowering the benefit becomes. The equality of the two opposing effects thus gives us the maximum level of UI provision that can be sustained in a symmetric equilibrium. The condition for the largest possible unemployment benefit level in a Ghent system with mobility $b^{g m}$ is (subscripts are omitted due to symmetry in all variables)

$$
\frac{u^{\prime}\left(\left(1-t\left(w, b^{g m}\right)\right) w\right)}{u^{\prime}\left(b^{g m}+\tilde{b}\right)}=\frac{\bar{L}-L(w)}{\bar{L}-L(w)+b^{g m} \frac{\bar{L}-L(w)}{C}}=\frac{C}{C+b^{g m}}
$$

At $b^{g m}$ for all sectors, no union has an incentive to lower its benefit level. They also have no incentive for deviating upward, as the induced inflow of migrants is given by

$$
\frac{\delta M_{i}\left(b_{i}, b_{-i}\right)}{\delta b_{i}}=\frac{(N-1)(\bar{L}-L(w))}{C} .
$$

For $N=2$, the outflow induced by lowering benefits equals the inflow induced by an increase in benefits. For $N>2$, however, the inflow exceeds the outflow and leads to a larger change in the contribution rate. Thus, at $b^{g m}$,the utility loss of the working union members outweighs the utility gain for unemployed members. Note that, the lower $C$ is, the more sensitive migration is with respect to unemployment benefits and the costlier unemployment insurance becomes, i.e. $b^{g m}$ is decreasing in the upper bound of the migration cost $C$.

\section{The minimum level of UI in equilibrium}

Condition (14) defines the upper bound of symmetric equilibria. For $N=2$, condition (14) also defines a unique equilibrium. For $N>2$, there exists a whole range of symmetric equilibria below $b^{g m}$, in which unions have no incentives to either unilaterally lower or raise their benefit levels. As shown above, unilaterally lowering unemployment benefits lowers the trade union's total utility when $b<b^{g m}$. When increasing the benefits instead, the inflow of migrants would exceed the outflow due to lower benefits and would thus induce a larger change in the contribution rate.

The lower bound of symmetric equilibria is determined by an unemployment benefit level, below which, even with the inflow of unemployment benefit recipients from all other 
industries, a rise in the benefit level increases the utility of unemployed members more than it lowers the utility of working members through the increase of the contribution rate. The lower limit $\underline{b}$ can be implicitly defined ${ }^{8}$ by using derivative (11a) in the first order condition (13)

$$
\frac{u^{\prime}((1-t(w, \underline{b})}{u^{\prime}(\underline{b}+\tilde{b})}=\frac{\bar{L}-L(w)}{\bar{L}-L(w)+\underline{b} \frac{(N-1) \bar{L}-L(w)}{C}}<\frac{C}{C+b^{g m}}
$$

The range of possible symmetric equilibria

We have shown that, with labor mobility, strategic benefit setting by unions will lead to a race the bottom in the level of UI provision in a system of decentralized Ghent UI. As, for $N=2$, multiple equilibria exist, this induces a coordination problem among trade unions. The equilibrium with the maximum sustainable level of UI may serve as a focal point in the range of possible equilibria. This maximum level of UI sustainable in equilibrium is falling as the upper boundary $C$ in the distribution of migration costs decreases and hence migration costs are reduced.

\subsubsection{Ghent UI: Wage and employment effect and summary of results}

As the maximum unemployment benefit level $b^{g m}$ is only implicitly given by (14), we cannot explicitly solve for the corresponding wage level $w^{g m}$. However, noting that the first order condition of (12) with respect to the wage level will equal (6) under a symmetric equilibrium in benefit levels, we can infer that, when the trade union can only imperfectly insure its member in case of unemployment, it will lower the wage level below $w^{g a}$ to provide more members with the higher utility level of employment. The introduction of welfare migration in a system of decentralized Ghent UI thus causes a race to the bottom for insurance provision, but also implies lower wages and higher employment. This result is summed up in Proposition 2.

Proposition 2 (Ghent UI under labor mobility): For a system of decentralized

Ghent UI with pure welfare migration,

(i) full UI is not sustainable in a symmetric equilibrium;

\footnotetext{
${ }^{8} \underline{b}$ is restricted to non-negative values. Should, for certain parameter constellations, the ratio of marginal utilities in condition (16) be so low to require negative values of $\underline{b}, \underline{b}=0$ applies.
} 
(ii) the maximum level of UI sustainable in a symmetric equilibrium is rising in migration costs;

\section{Centralized UI and the fiscal externality problem}

We apply the term centralized UI to a comprehensive, government-run UI that spans the entire economy and thus the domains of all trade unions. The central government moves first and sets the level of unemployment benefits.

$$
t\left(w_{1}, w_{2}, \ldots, w_{N}, b\right) \sum_{i=1}^{N}\left(w_{i} L_{i}\left(w_{i}\right)\right)=b \sum_{i=1}^{N}\left(\overline{L_{i}}-L_{i}\left(w_{i}\right)\right) .
$$

The contribution rate $t$ is set by the central government to balance the budget after wage setting by the trade union and employment adjustments by firms. Since the same unemployment benefit level applies to all individuals, no welfare migration occurs in this setting.

For any trade union $j$, the maximization problem is similar to that of the no-mobility Ghent union in (4), but it takes the unemployment benefit payment $b$ as given and solves the maximization problem (4) only with respect to the wage $w_{j}$. The first order condition is

$$
\begin{gathered}
\Omega_{w_{j}}=\eta\left[u\left(\left(1-t\left(w_{j}, w_{-j}, b\right)\right) w_{j}\right)-u(b+\tilde{b})\right] \\
+w_{j} u^{\prime}\left(\left(1-t\left(w_{j}, w_{-j}, b\right)\right) w_{j}\right)\left[1-t\left(w_{j}, w_{-j}, b\right)-w_{j} \frac{\delta t\left(w_{j}, w_{-j}, b\right)}{\delta w_{j}}\right]=0 .
\end{gathered}
$$

The trade union $j$ takes into account that the government adjusts the contribution rate to balance (3c), i.e. $\delta t\left(w_{j}, w_{-j}, b\right) / \delta w_{j}$. For $N=1$, the optimal wage is equivalent to that of a Ghent union that faces no labor mobility: full UI at $\left(w^{g a}, b^{g a}\right)$ can be established regardless of whether the government or the trade union decides on the unemployment benefit level. For the general case of $N \geq 1$ the derivative of the tax rate with respect to the wage set by union $j, w_{j}$ given by

$$
\frac{\delta t\left(w_{j}, w_{-j}, b\right)}{\delta w_{j}}=-\frac{t L_{j}\left(w_{j}\right)(1+\eta)}{\sum_{i=1}^{N}\left(w_{i} L_{i}\left(w_{i}\right)\right)}-\eta \frac{L_{j}\left(w_{j}\right)}{w_{j}} \frac{b}{\sum_{i=1}^{N}\left(w_{i} L_{i}\left(w_{i}\right)\right)}>0 .
$$


It is not possible to solve (16) and (17) for $w_{j}$ analytically, but equation (17) is just a generalization of the case $N=1$, which again is identical to that of a single Ghent UI under no labor mobility from (3a). For $N>1$, multiplying the derivative of (3a) with

$$
0<\frac{w_{j} L_{j}\left(w_{j}\right)}{\sum_{i=1}^{N}\left(w_{i} L_{i}\left(w_{i}\right)\right)}<1 .
$$

yields (17). The more sectors there are, the lower is the effect a wage increase by union $j$ has on the uniform contribution rate $t$. The centralized UI thus faces a negative fiscal externality: the more unions there are in the centralized UI, the lower is the induced increase in the contribution rate for a unilateral wage rise. The single union can shift the cost of a unilateral wage increase to the workers of other unions. The trade union $j$ only considers the reduced negative impact for its own employed members; the cost imposed on the other unions' employed members does not enter its objective function. Consequently, wages are set too high. Therefore, the centralized system of UI does not allow full insurance at the labor-rent maximizing wage rate $w^{g a}$ (and thus at the highest possible utility level for employed and unemployed individuals). ${ }^{9}$

As unemployment benefits are set uniformly for the members of all trade unions, full unemployment insurance requires symmetric wage setting by all trade unions. Positing full UI ( $b$ satisfying (5)) and symmetric wages, the first order condition (16) together with the partial derivative of the contribution rate in (17) gives us an implicit solution for the wage rate $w^{c e}$, where ce denotes the results for a centralized UI system:

$$
w^{c e}=\tilde{b} \frac{\bar{L}(N-1-\eta)-L^{c e}\left(w^{c e}\right)(N-1)}{\bar{L}(-1-\eta)-L^{c e}\left(w^{c e}\right)(N-1)} .
$$

Equation (18) is a generalization of (8) that determines the optimal wage $w^{g a}$ for a Ghent union in a setting without labor mobility by allowing for $N>1$. Numerical simulation yields two solutions of (18) for $w^{c e}$, one larger and one smaller than $w^{g a}$. However, as the smaller one violates the requirement $L(w) \leq \bar{L}$ in the budget constraint (3c), there exists only one solution of the problem with $w^{c e}>w^{g a}$ and with $w^{c e}$ increasing in $N$. As the term $\bar{L}(N-1-\eta)$ increases, $w^{c e}$ increases. $^{10}$

\footnotetext{
${ }^{9}$ See Appendix.

${ }^{10}$ For very high values of $N$, the denominator of (15) will turn negative and full insurance is no longer possible. Numerical simulations with realistic parameter settings have shown that this occurs only at extremely large values of $N$ (around 1.000.000).
} 
Taking into account that labor rents were maximized at $w^{g a}$, the comparatively higher gross wage demands of multiple trade unions within a centralized UI imply a lower employment level and thus lower labor rents. Thus, full insurance can only be achieved at a lower net income level than in the Ghent equilibrium $\left(w^{g a}, b^{g a}\right)$ without labor mobility. Taken together, these arguments yield Proposition 3.

\section{Proposition 3: In centralized UI,}

(i) a symmetric equilibrium with full unemployment insurance exists for small enough $N$;

(ii) a gross wage $w^{c e}$ strictly larger than $w^{g a}$ that maximizes labor rent is set

(iii) the equilibrium gross wage $w^{c e}$ is an increasing function of $N$;

(iv) net wages and unemployment benefits are lower than the equilibrium $\left(w^{g a}, b^{g a}\right)$ in the Ghent UI system without labor mobility.

In centralized UI, trade unions are able to partially externalize the costs of unemployment through the centralized insurance system. This exerts an upward pressure on wages. Although the government is able to set the unemployment benefit level such that full unemployment insurance exists in a symmetric equilibrium in wages, due to the fiscal externality problem, equity among employed and unemployed individuals comes at the expense of a lower workers' income. At a symmetric wage equilibrium with full UI, the wage $w^{c e}$ is strictly larger than the wage rate $w^{g a}$ that maximizes labor rents. Unemployment is higher than at $w^{g a}$ and both net wages and unemployment benefits are lower.

\section{A coordinated system of unemployment insurance}

The previous sections have shown that, in the presence of mobile workers, a decentralized Ghent system of UI leads to a race to the bottom in unemployment benefits, and that a centralized system of UI creates a negative fiscal externality that leads to higher gross wages and aggregate unemployment levels. This fiscal externality in centralized UI is due to the uniform contribution rate rather than to a common unemployment benefit level. The race to the bottom in a Ghent UI system, on the other hand, is due to the decentralized setting of unemployment benefit levels rather than to decentralized funds and contribution rates. An ideal system of UI thus should incorporate decentralized balanced budgets and decentralized contribution rates that overcome the fiscal externality problem as well as centrally determined 
unemployment benefit levels that inhibit strategic, decentralized setting of unemployment benefit levels by trade unions to prevent a race to the bottom. This can be achieved by decentralized trade unions that run their UI schemes independently but, at the same time, are committed to one single uniform unemployment benefit level $b=b_{j} \forall j$ for all sectors. We call this system a coordinated UI - a hybrid between decentralized and centralized UI systems.

Each union now faces a similar insurance budget constraint as a Ghent union (see equation (3a)), but with only one unemployment benefit level $b$ mandatory for all insurance schemes, that is agreed upon in a first stage. It is thus deprived of one policy instrument:

$$
t_{i}\left(w_{i}, b\right) w_{i} L_{i}\left(w_{i}\right)=b\left(\bar{L}-L_{i}\left(w_{i}\right)\right)
$$

The central setting of the unemployment benefit level eliminates any incentive for mobile unemployed individuals to move into another UI, so that welfare migration does not affect the insurance budget constraints. For any common unemployment benefit level $b$, unions will set wages taking account the fact that the contribution rate $t_{i}$ is determined endogenously within their own UI schemes according to (3d):

$$
\begin{gathered}
t_{i}\left(w_{i}, b\right) w_{i} L_{i}\left(w_{i}\right)=b\left(\bar{L}-L_{i}\left(w_{i}\right)\right), \\
t_{j}\left(w_{j}, b\right)=\frac{b}{w_{j}} \frac{\bar{L}-L_{j}\left(w_{j}\right)}{L_{j}\left(w_{j}\right)} .
\end{gathered}
$$

s.t.

The first order condition is similar to (6), but with the common level of benefits $b$.

$$
\begin{gathered}
\Omega_{j w_{j}}=\eta\left[u\left(\left(1-t_{j}\left(w_{j}, b\right)\right) w_{j}\right)-u(b+\tilde{b})\right]+ \\
w_{j} u^{\prime}\left(\left(1-t_{j}\left(w_{j}, b\right)\right) w_{j}\right)\left[1-t_{j}\left(w_{j}, b_{j}\right)-w_{j} \frac{\delta t_{j}\left(w_{j}, b\right)}{\delta w_{j}}\right]=0, \\
\frac{\delta t_{j}\left(w_{j}, b\right)}{\delta w_{j}}=-\frac{t_{j} L_{j}\left(w_{j}\right)(1+\eta)+b \frac{L_{j}\left(w_{j}\right)}{w_{j}} \eta}{w_{j} L_{j}\left(w_{j}\right)} .
\end{gathered}
$$

with

Given the similarity to the wage setting of a trade union in a Ghent UI system without labor mobility (6), we can infer that setting the unemployment benefit level $b^{g a}$ as derived in (8) also fulfills the first order condition (20). For the wage rate $w^{g a}$ and unemployment benefit 
level $b^{g a}$, (3d) implies that full insurance (5) holds. Hence, $b^{g a}$ implements full unemployment insurance in a coordinated UI system. while leading the decentralized trade unions to set the same gross wage as in the hypothetical case of a Ghent system without labor mobility.

Which common unemployment benefit level $b$ would be chosen? Each trade union prefers the unemployment benefit level that maximizes the utility of its members, given its own wage setting behavior as determined by the first order condition (20) and its insurance budget constraint (3d). Since the common unemployment benefit level implies that welfare migration can be ignored, the preferred benefit level is determined by

$$
\max _{b} \Omega_{i}\left(w_{i}\right)=L_{i}\left(w_{i}\right) u\left(\left(1-t_{i}\left(w_{i}, b\right)\right) w_{i}\right)+\left(\bar{L}-L_{i}\left(w_{i}\right)\right) u((b+\tilde{b})),
$$

subject to (3d) and (20). The first order condition of the objective function with the insurance budget constraint alone simplifies to the equivalent of the full insurance condition (5)

$$
\left(1-t_{i}\left(w_{i}, b\right)\right) w_{i}=b_{i}+b
$$

Together with the wage setting condition (20), this implies that each union prefers

$$
b^{c o}=\frac{\eta^{\eta}}{(1+\eta)^{1+\eta}} \frac{b^{1+\eta}}{\bar{L}}=b^{g a} .
$$

When jointly implementing unemployment benefit level $b$ for all decentralized insurance schemes, no trade union gains from supporting a different unemployment benefit level. In a Coordinated UI system, unions will thus set the unemployment benefit level $b^{c o}=b^{g a}$ and then set the decentralized gross wages $w^{c o}=w^{g a}$, providing full UI while maximizing labor rents. The result is summed up in Proposition 4.

\section{Proposition 4: With coordinated UI,}

i) it is possible to implement the unemployment benefit level $b^{c 0}=b^{g a}$ such that all trade unions set the gross wage $w^{c o}=w^{g a}$ that maximizes the labor rent;

(ii) at $\left(w^{c o}, b^{c o}\right)$ the unemployment insurance provides full insurance;

ii) $\quad b^{c o}=b^{g a}$ is the preferred unemployment benefit level of all trade unions and will be unanimously agreed upon in a coordination procedure.

A coordinated system of UI performs better with respect to income equalization than the Ghent system, since it inhibits strategic setting of unemployment benefit levels and hence a 
race to the bottom in UI coverage. It achieves higher employment levels than centralized UI for the same degree of insurance coverage, as it avoids the negative fiscal externality and thus ensures lower wages and higher employment levels.

\section{Conclusion}

This paper reconciles two previously separate arguments relevant to the design of UI. UI belongs to the wider class of redistributive systems which may break down in the presence of labor mobility, in particular if migration motivated by the level of welfare benefits exists. In the case of independent Ghent insurance systems, a race to the bottom of the unemployment insurance levels occurs through the strategic setting of unemployment benefit levels, to avoid migration into and encourage emigration out of the own unemployment insurance scheme. Centralization eliminates such strategic behavior and can thus avoid the incentives to engage in a "race to the bottom" of social insurance, but this comes at a cost: A centralized unemployment insurance system creates a negative fiscal externality that leads trade unions to set excessively high wages, because the shared insurance budget allows each single trade union to shift part of the cost of higher wages to other unions. Whilst strategic interaction via the unemployment benefit level destabilizes redistribution by decentralized Ghent unemployment insurance schemes, strategic setting of wages through the centralized insurance budget causes excess wages, resulting in excessive unemployment. By introducing a hybrid system, i.e. a coordinated system of UI, one can both avoid the race to the bottom in the presence of welfare migration and the negative fiscal externality by setting a common unemployment benefit level without creating a common budget.

Coordinated UI unequivocally is preferable to centralized UI. For the same degree of full unemployment insurance provision, coordinated UI leads to lower unemployment and higher net incomes for employed and unemployed individuals. The moderation of union wage demands caused by the separate UI funds of different unions leads to a maximization of total labor rents when full insurance is chosen, which are then equally distributed among employed and unemployed union members. The resulting net income is therefore higher than in the case of centralized UI. In centralized UI, full UI provision results in a gross wage setting that is above the labor rents maximizing value, leading to higher unemployment, UI contributions rates and lower net incomes. 
Ghent UI in a setting with labor mobility results in a lower degree of UI provision than Coordinated UI, but also lower unemployment. From the perspective of maximizing the aggregate utility of workers (the maximization objective of trade unions), coordinated UI is preferable as it provides full insurance at the highest possible income level. However, from a perspective of social welfare maximization that includes factor returns on capital, the outcome of Ghent UI with lower unemployment and gross wages may be preferred over the outcome of coordinated UI with full insurance at higher incomes of employed and unemployed individuals, but also higher unemployment and implicitly lower returns on capital.

Coordinated UI does not necessarily have to be provided at full insurance coverage, however. We have only shown above that trade unions, were they to decide collectively on which benefit level to implement, would choose $b^{c o}=b^{g a}$. It is nevertheless perfectly possible to conceive of settings, in which the benefit level would be coordinated not by the unions but by the government, that then could take into account further factors such as capital returns. If the degree of UI provision can be set freely, the result of Ghent UI under labor mobility can be implemented by a coordinated UI as well. The same degree of UI provision as that resulting from (uncoordinated) Ghent UI will, if implemented in a coordinated UI system, lead to the same wage and unemployment results as Ghent UI. Coordinated UI is thus weakly preferable to Ghent UI, as it can always implement the latter's results, but also results with higher UI coverage (and thus somewhat higher unemployment levels), depending on social preferences.

Indeed, this possibility to choose UI levels in coordinated UI completes the argument why coordinated UI is preferable to centralized UI. In the latter case, where the government chooses the degree of UI provision, settings with incomplete insurances are also possible, depending on the objectives of the government in setting UI. However, coordinated UI would, due to the absence of a fiscal externality, always produce lower unemployment, higher net incomes and hence also higher capital returns for the same degree of UI provision, ensuring that it always leads to a strictly better result.

Our formal analysis used a highly stylized setting with $N$ trade unions in symmetric industries, between which individuals may be mobile in order to bring out the 'pure' effects of UI centralization or decentralization. Nevertheless, some preliminary policy conclusions are worth mentioning. In the case of a closed economy, the choice of unemployment benefit levels is essentially restricted to the national or industry level. Our model would thus suggest 
that a coordinated decentralization of UI from national to union level may lead to more efficient wage setting and lower unemployment. The case of several countries, between which individuals are mobile, is more complicated as now essentially three levels exist: the central, supra-national level, the national level and the industry or trade union level (as most countries have unions at industry level). Here, our model would predict that, although a coordinated UI at industry level should bring about the best results with regard to productive (wage) efficiency, coordinating national insurances should still be preferable to a UI system centralized at supra-national level, as the wage inefficiency rises in the number of unions sharing the insurance scheme, thus peaking at full UI centralization.

In the case of the European Union, the analysis in this paper would, solely in view of the incentives for wage setting trade union actors, support a form of harmonization of welfare standards in UI rather than a centralized EU unemployment insurance as part of an effort to stabilize welfare systems against pressures arising from possible welfare migration. An EU unemployment insurance has repeatedly been proposed, mainly as a transfer and stabilization mechanism that insures countries against asymmetric shocks. Our analysis provides several insights for this debate, even though the model setting in this paper is highly stylized and thus differs from the EU reality in several aspects. Nevertheless, if migration incentivized by the generosity of unemployment benefits is possible, our analysis shows that the threat of a "race to the bottom” in welfare standards exists for decentralized UI systems as in the EU case. Also, the effects of centralization of UI developed here - inhibition of a "race to the bottom" but negative employment effects - would carry over to the EU case. However, a straightforward application of a coordinated UI for the EU would probably not be advisable. Labor markets in EU member states are not symmetric as in our model and a common benefit level would thus be too high for some member states and too low for others, leading to suboptimal redistribution and labor market outcomes. In practice, the concept would have to be adjusted to adjust for such considerations. A coordination on different, specified levels of unemployment benefits may be a viable adjustment of the "pure" concept that accommodates asymmetry between labor markets. The extent of welfare migration due to different benefit levels might then be kept in check by minimum migration costs or the existence of access restrictions to welfare systems for intra-EU migrants.

Our analysis shows that one has to take unionization of labor markets and the resulting strategic interactions between nationally operating trade unions into account when assessing 
the pros and cons of a European centralized UI system and should consider developing alternatives, such as a coordinated European UI system. 


\section{References}

Alesina, A. and Perotti, R. (1997): “The Welfare State and Competitiveness”, American Economic Review 87(5), 921-939.

Beine, M., Docquier, F. and Özden, C. (2011): "Diasporas”, Journal of Development Economics 95, 30-41.

Böckerman, P. and Uusitalo, R. (2006): "Erosion of the Ghent System and Union Membership Decline: Lessons from Finland”, British Journal of Industrial Relations 44(2), 283-303.

Borjas, G. J. (1999): Immigration and welfare magnets. Journal of labor economics 17(4), 607-637.

Brueckner, J. K. (2000): "Welfare Reform and the Race to the Bottom: Theory and Evidence”, Southern Economic Journal 66 (3), 505-525.

Brücker, H., Epstein, G. S., McCormick, B., Saint-Paul, G., Venturini, A. and Zimmermann, K. F. (2002): "Managing migration in the European welfare state", in: Boeri, T., Hanson, G. and McCormick, B. (eds), Immigration policy and the welfare system, Oxford, 1-168.

Calmfors, L. and Driffill, J. (1988): "Bargaining Structure, Corporatism and Macroeconomic Performance”, Economic Policy 3(6), 14-61.

Cremer, H. and Pestieau, P. (2004): “Factor mobility and redistribution”, in Henderson, J. and Thisse, J.-F. (eds.) Handbook of Regional and Urban Economics IV, 2529-2560.

Dahlberg, M. and K. Edmarks (2008): "Is there a "race-to-the-bottom" in the setting of welfare benefit levels? Evidence from a policy intervention”, Journal of Public Economics 92, 1193-1209.

Dimick, M. (2012): “Labor Law, New Governance, and the Ghent System”, North Carolina Law Review 90(2), 319.

Dolls, M., Fuest, C., Neumann, D., Peichl, A. (2014): An Unemployment Insurance Scheme for the Euro Area? A Comparison of Different Alternatives Using Micro Data, ZEW Centre for European Economic Research Discussion Paper No. 14-095, October

Dullien, S. (2007): Improving Economic Stability in Europe. What the Euro Area can learn from the United States' Unemployment Insurance, Working Paper , SWP - German Institute for International and Security Affairs, July.

Dullien, S. and Schwarzer, G. (2011): "Making Macroeconomic Stabilization Work: Lessons from the Crisis for the EU Buget Debate”, in Begg, D. et al. (eds.), European Economic Governance: Impulses for Crisis Prevention and New Institutions, Bertelsmann Foundation: Gütersloh, 93-119.

Freeman, R. and Gibbons, R. (1993):"Getting together and breaking apart, the decline of centralized collective bargaining” in Freeman, R. and Katz, L. (eds.): Differences and Changes in Wage Structures, Cambridge, MA: NBER, 45-370.

de Giorgio, G. and M. Pellizzari (2006): Welfare Migration in Europe and the Cost of a Harmonised Social Assistance, IZA Discussion Paper No. 2094, April.

Groot, L. (2001): “Tax Level and Tax Internalization Effects on Union Wage Bargaining”, De Economist 149(6) , 219-232.

Holmlund, B., Löfgren, K. G. and Engström, L. (1989): Trade Unions, Employment, and Unemployment Duration, Clarendon Press: Oxford.

Holmlund, B. and Lundborg, P.(1999): "Wage bargaining, union membership, and the organization of unemployment insurance”, Labour Economics 6, 397-415.

Katz, H. (1993): "The Decentralization of Collective Bargaining: A Literature Review and Comparative Analysis”, Industrial and Labor Relations Review 47 , 3-22.

Kvist, J. (2004): "Does EU enlargement start a race to the bottom? Strategic interaction among EU member states in social policy”, Journal of European Social Policy 14(3), 301318.

Lejour, A. and Verbon, H. (1996): "Capital mobility, wage bargaining, and social insurance policies in an economic union”, International Tax and Public Finance 3(4), 495-513.

Nickell, S. and Layard, R. (1999): "Labor Market Institutions and Macroeconomic Performance" in Ashenfelter, O. and Card, D. (eds.): Handbook of Labor Economics III, 3029-3084. 
Nickell, W. (2006): The CEP-OECD Institutions Data Set 1960-2004, Discussion Paper 759, Centre for Economic Performance, London School of Economics and Political Science.

Oswald, A. (1985): “The Economic Theory of Trade Unions: A Survey”, Scandinavian Journal of Economics 87(2), 160-193.

Razin, A. and J. Wahba (2011): Welfare Magnet Hypothesis, Fiscal Burden and Immigrant Skill Selectivity, NBER Working Paper No. 17515, October.

Skupnik, C. (2014): "EU enlargement and the race to the bottom of welfare states", IZA Journal of Migration 3(1), 1-21.

Van Rie, T., Marx, I. and Horemans, J. (2011): “Ghent revisited: Unemployment insurance and union membership in Belgium and the Nordic countries", European Journal of Industrial Relations 17 (2), 125-139.

Sinn, H.-W. (2000): The New Systems Competition, Blackwell: Malden, MA.

Tiebout, C. (1956): “A Pure Theory of Local Public Expenditures”, The Journal of Political Economy, 64(5), 416-424.

Van Rompuy, H., Barroso, J.M., Juncker, J.C., Draghi, M. (2012): Towards a Genuine Economic and Monetary Union, Report to the European Council Meeting, December $13 / 14$.

Vetter, S. (2014): Stabilisation, solidarity or redistribution? Does the eurozone need a common unemployment insurance scheme - and if so, for what?, Deutsche Bank Research Briefing, November 25. 


\section{Appendix}

Under Centralized UI, full unemployment insurance cannot be provided at the labor-rents maximizing wage.

Proof: Full unemployment insurance for all unions requires a symmetric equilibrium in wages, since only one benefit level and one tax rate exist in centralized UI. At the benefit level $b^{g a}$, any symmetric equilibrium in wages in a centralized UI system implies wages strictly larger than $w^{g a}$ : A symmetric equilibrium in wages at $w^{g a}$ exists if the first order condition of the unions' wage setting problem in a centralized UI system (16) under benefit $b^{g a}$ is satisfied at $w_{i}=w^{g a} \forall i$. If (13) is not satisfied and the expression on the LHS takes a positive sign at $w^{g a}$, unions will set higher wages than $w^{g a}$.

$$
\begin{aligned}
\Omega_{w_{j}} & =\eta\left[u\left(\left(1-t\left(w_{j}, w_{-j}, b\right)\right) w_{j}\right)-u(b+\tilde{b})\right]+\mid \\
& +w_{j} u^{\prime}\left(\left(1-t\left(w_{j}, w_{-j}, b\right)\right) w_{j}\right) \\
& {\left.\left[1-t\left(w_{j}, w_{-j}, b\right)-w_{j} \frac{\delta t\left(w_{j}, w_{-j}, b\right)}{\delta w_{j}}\right]\right|_{b=b^{g a} ; w_{i}=w^{g a} \forall i} }
\end{aligned}
$$

Under $b=b^{g a}$ and $w_{i}=w^{g a} \forall i$, we know from section 3.1 that the condition for full insurance (5) holds. Thus, the first expression in square brackets is equal to zero. Also, $w_{j} u^{\prime}\left((1-t) w_{j}\right)>0$ around $w^{g a}$. The sign of the entire expression is thus determined by

$$
\left[1-t\left(w_{j}, w_{-j}, b^{g a}\right)-w \frac{\delta t\left(w_{j}, w_{-j}, b^{g a}\right)}{\delta w_{j}}\right],
$$

which must equal zero in the case of $N=1$ due to the equivalence of this case with the nomobility Ghent union case, where $w^{g a}$ satisfies the first-order condition (6).

As we know that $\delta t\left(w_{j}, w_{-j}, b^{g a}\right) / \delta w_{j}>0$ is strictly smaller in the case of $N>1$ than if $N=1$, the sign of (A2) at $w_{i}=w^{*} \forall i$ must be positive for $N>1$, implying(A1) to be positive. Finally, note that, as the tax rate effect is diminished compared to the case of $N=1$ by the factor $-w_{j} L_{j}\left(w_{j}\right) / \sum_{i=1}^{N}\left(w_{i} L_{i}\left(w_{i}\right)\right)$, this effect increases as all wages rise, since $\delta\left(w_{i} L_{i}\left(w_{i}\right)\right) / \delta w_{i}<0 \forall i$, implying that a symmetric equilibrium in wages at benefit level $b^{g a}$ exists for some $w_{i}>w^{g a} \forall i$, However, the budget constraint (3c) and the full insurance condition (5) imply that under centralized UI, $b^{g a}$ is the unique benefit level providing full insurance in a symmetric wage equilibrium at the labor-rents maximizing wage, $w_{i}=w^{g a} \forall i$, 
so at the equilibrium $w_{i}>w^{g a} \forall i$ at $b^{g a}$, there will be neither full insurance nor fulfillment of the budget constraint. 